Please cite this article as: Puig, R., Kiliç, E., Navarro, A., Albertí, J., Chacón, L., Fullana-iPalmer, P. 2017. Inventory analysis and carbon footprint of coastland-hotel services: a Spanish case study. Science of the Total Environment, 595, 244-254. http://dx.doi.org/10.1016/j.scitotenv.2017.03.245

4

\title{
Inventory analysis and Carbon footprint of coastland-hotel services: a Spanish case study
}

\author{
Rita Puig $^{2,3^{*}}$, Eylem Kiliç ${ }^{1}$, Alejandra Navarro ${ }^{2,3}$, Jaume Albertí $^{4}$, Lorenzo Chacón ${ }^{5}$, \\ Pere Fullana-i-Palmer ${ }^{3,4}$ \\ ${ }^{1}$ Usak University, 1 Eylul Campus, 64200 Usak, Turkey. \\ ${ }^{2}$ GIR, Escola d'Enginyeria d'Igualada (EEI), Universitat Politècnica de Catalunya (UPC, \\ Barcelona tech), Pla de la Massa, 8, 08700 Igualada, Spain. \\ ${ }^{3}$ Cyclus Vitae Solutions, S.L., Avinguda Caresmar 33, 1; 08700 Igualada, Spain \\ ${ }^{4}$ UNESCO Chair in Life Cycle and Climate Change (ESCI-UPF), Pg. Pujades 1, 08003 \\ Barcelona, Spain. \\ ${ }^{5}$ Instituto Andaluz de Tecnología, C/ Leonardo Da Vinci 2, 41092 Sevilla, Spain
}

*Corresponding author: Rita Puig, Tel.:+34938035300. E-mail address: rita.puig@eei.upc.edu

\begin{abstract}
Tourism is a key industry in the Spanish economy. Spain was in the World top three ranking by international tourist arrivals and by income in 2015. The development of the tourism industry is essential to maintain the established economic system. However, if the environmental requirements were not taken into account, the country would face a negative effect on depletion of local environmental resources from which tourism depends. This case study evaluates, through a life cycle perspective, the average carbon footprint of an overnight stay in a Spanish coastland hotel by analyzing 14 two-to-five-stars hotels. Inventory and impact data are analyzed and presented both for resource use and greenhouse gases emissions, with the intention of helping in the environmental decision-making process. The main identified potential hotspots are electricity and fuels consumption (6 to $30 \mathrm{kWh} /$ overnight stay and 24 to $127 \mathrm{MJ} /$ overnight stay respectively), which are proportional to the number of stars and unoccupancy rate and they produce more than $75 \%$ of the impact. It is also revealed that voluntary implementation of environmental monitoring systems (like EMAS regulation) promotes collection of more detailed and accurate data, which helps in a more efficient use of resources. A literature review on LCA and tourism is also discussed. Spanish hotels inventory data presented here for the first time will be useful for tourism related managers (destination managers, policy makers and hotel managers among others) to calculate sustainability key indicators, which can lead to achieve real sustainable-tourism goals. Further data collection will be needed in future projects to gather representative data from more hotels, other accommodation facilities and also other products/services offered by tourist sector in Spain (like transport of tourists, food and beverage, culture-sports \& recreation and others).
\end{abstract}

Key words: accommodation environmental impact, life cycle perspective, inventory data, greenhouse gases emissions, coastal tourism, tourism sustainability 


\section{Introduction}

Tourism industry, which is responsible for 5\% of global emission of $\mathrm{CO}_{2}(\mathrm{UNWTO}, 2008)$, is one of the two largest sectors of Spanish economy in terms of employment and economic activity. Spain ranked second in 2014 and third in 2015 in income from international tourism worldwide with 65 billion and 56.5 billion US\$ respectively; and third in arrivals both in 2014 and 2015 with 65 and 68.2 million overnight visitors (UNWTO, 2015; UNWTO 2016). Particular attention should be paid to resource consumption and $\mathrm{CO}_{2}$ emissions of tourism industry, considering its significant growth (Cerutti et al., 2016). In Spain, tourist population is often concentrated in coastal regions, where local natural environment is a key factor of tourist attraction. Although the increase of tourist arrivals in these areas is essential to maintain the established economic system, the increment of tourist population may significantly increase the depletion of local natural resources and may cause deterioration of the local ecosystem due to construction of new infrastructure and continuous pollution, unless an accurate design of the activity pays the needed attention to the environmental requirements (Köberl et al., 2016). Environmental concerns for the natural and economic environments place emphasis on the inclusion of sustainability in the tourism sector and on accurate identification and assessment of the environmental impacts.

Life cycle assessment (LCA) is a widely accepted methodology that has proven its efficiency on figuring out environmental performance improvement opportunities and definition of sustainability strategies for many industries including tourism and individual tourism events (El Hanandeh, 2013; Michailidaou et al., 2016). As stated by UNEP/SETAC Life Cycle Initiative (UNEP/SETAC, 2012): "If the green economy is to bring the necessary changes to guarantee a future for life on Earth, decision making on product sustainability, investment, and policy must be made using life cycle thinking and operationalized through life cycle management, approaches, and tools". A life cycle approach to impact assessment enables product and services designers, service providers, companies, government agencies and individuals to make choices for the longer term, by considering impacts on all environmental media (i.e. air, water, land) in a systemic and holistic way.

A fully-fledged LCA is not always needed but a Life Cycle Management (Rebitzer et al., 2001) point of view is essential to assess systems' impact, if environmental shifting is to be avoided (Fullana-i-Palmer et al., 2011). The carbon footprint (CF) of a product or service is one of the impact categories evaluated through a LCA study, although it has its own specific standards, such as ISO 14067 (ISO 14067, 2013), and sometimes is used as a proxy for the whole set of impact categories (Bala et al., 2010). A CF-LCA approach could be a scientific supporting tool for environmental communication and education of tourists and an objective instrument for a more responsible consumption, by measuring the environmental burdens and provide a reliable assessment of greenhouse gas emissions associated with tourist accommodation (Michailidaou et al., 2016, De Camillis et al., 2010).

Our research aims to provide inventory data regarding one overnight stay in Spanish coastland hotels with different star ratings (the standard quality classification indicator for hotels), and propose resource consumption averages that can be useful to establish best practices to promote hotels' environmental performance. 
Inventory data presented in this paper has an added value since, to our knowledge, default values for Spanish hotels were provided for the first time. In addition, this is in line with the Sustainable Tourism Program (of the 10-Year Framework of Programs on Sustainable Consumption and Production Patterns) and where the UNEP/SETAC life cycle initiative strives to identify key performance indicators for a sustainable tourism private sector (UNEP, 2017). The relative size of the global tourism sector, its scale of consumption and level of impacts on the environment needs an urgent and imperative response. Sustainable tourism indicators were also considered part of an early warning system for destination managers and a key tool for measuring and monitoring change. The main impacts due to consumptions in domestic tourism are (OECD, 2016): passenger transport (22\%), accommodation (18\%), food and beverage (17\%), culture-sports \& recreation (7\%), travel agencies (4\%) and others (32\%). Publishing inventory data is really necessary because inventory (not impacts) is what is needed and can be introduced in either tool or model for sustainability tourism management. Destination managers and policy makers need urgently tools to evaluate and improve the sustainability of tourism in an area (Blancas et al., 2011) and these tools need to be filled with inventory data, as much accurate as possible. This paper will contribute to Spanish sustainability of tourism by providing inventory data on hotel-accommodation which was not previously found in the literature.

This project is a preliminary step to make a contribution to the existing knowledge. Further analysis of more detailed and wider inventory will be investigated in the next phase of our work.

\section{Literature review: life cycle assessment $\&$ tourism}

In the last 15 years, an increasing number of studies on applications of LCA methodology in the field of tourism at different geographical locations with various system boundaries such as an island (Sun, 2014), a country (Perch-Nielsen et al., 2010), alternative travel choices (Filimonau et al., 2014), services provided in a holiday package (Filimonau et al., 2013) or individual hotel case studies (Hu et al., 2015) by adopting various flow references have been developed. Several approaches have been taken on the identification and evaluation of the environmental impacts of tourism sector. In this section, the published papers were classified in 5 different subsections to facilitate a complete overview: environmental impact assessment of tourism sector (where the more general LCA studies with different scopes can be found), environmental impact assessment of holiday packages (where specific touristic packages are evaluated), energy audits in hotel buildings (where energy consumption is audited and improved, but no other impacts are evaluated), life cycle energy analysis (where, not only the energy during the use phase of the hotel is considered, but also the embodied energy due to materials use for hotel construction and demolition) and, finally, environmental impact of food consumption (where the impacts due to the production of the consumed food are taken into account, which is rarely done otherwise).

\section{Environmental impact assessment of tourism sector}

A life cycle assessment case study was conducted to evaluate the environmental performance of accommodation services in order to identify hot spots of the service provided by two Italian hotels and introduce life cycle thinking into the decision making process (Balázs et al., 2004; De Camillis et al., 2008; Raggi et al., 2005). The functional unit was defined as an overnight stay of one guest for all case studies. Life cycle inventory data was collected on-site 
from two participating hotels, regarding accommodation services, transport of guests to the hotels and wastes produced by hotels. Authors implemented both normalization and weighting phases to the impact assessment. Nevertheless the detailed outcomes and life cycle inventory data of Italian hotels were not available. Findings from the previous case studies were reported and discussed by De Camillis et al. (2010). The main results from each case study highlighted the fact that global warming potential was the main impact category due to significant energy use of hotel services. The consumption of water for hotel activities was the second most significant issue related to resource use in Italian hotels. Authors also point out that exact interpretation of results and identification of improvement options were highly dependent upon collection of high quality inventory data, and more importantly, inventory data and interpretation had to be managed in a disaggregated way to highlight contributions of different services.

158 The findings from Italian LCA case studies had important implications, which revealed that LCA had a great potential for supporting efficient internal data management and resource optimization. Furthermore LCA could serve as an effective tool for environmental performance improvement and supporting environmental communication and education for tourists, to provide a more responsible consumption.

Kuo and Chen (2009) adopted a comprehensive life cycle approach and analyzed the environmental loads of touristic services by considering entire tourism sector of Penghu Island in Taiwan, where tourist transportation, accommodation and recreation activities were all considered. It is one of the detailed studies on mass tourism in Asian countries with available inventory data regarding tourist activities such as sightseeing, historic site visiting, landscape visiting, motorized water activity, swimming, nature watching, rafting, fishing and other. The energy use and related $\mathrm{CO}_{2}$ emissions of transportation, different accommodation types, recreation activities, and environmental loads per tourist per trip in Penghu Island were also reported.

Another preliminary attempt was made by Castellani and Sala (2012) to compare the results of LCA and Ecological Footprint (EF) methods to investigate the possibility of using two approaches for sustainability assessment of accommodation services. The environmental impact calculation per overnight accommodation was performed for seven different accommodation types such as 1-2-star hotel, 3-star hotel, 4-star hotel, camping site, agritourism, bed and breakfast and second home. Additionally, a comprehensive and detailed inventory data on seven kinds of accommodation was introduced. The results highlighted the significance of the implementation of LCA to the tourism sector, which have important potential to support decision making (due to its broader view, ie. life cycle approach and evaluation of many impact categories), and its combined use with the EF of tourism. The combination of both methodologies is very interesting because although LCA is more comprehensive in terms of coverage of impact categories it disregards the carrying capacity of the system and its limit of resource, which is assessed by EF.

\section{Environmental impact assessment of holiday packages}

Chambers (2004) used LCA methodology to compare and analyze the differences between two package holidays in Bulgaria, which could offer both holiday types within an European context. Data on hotels were collected in the form of 'per passenger per night', 'per passenger per package', and 'per study group per package'. Inventory data related to energy use, water use, chemical use and solid waste production for two types of Bulgarian holiday package was 
reported. Greenhouse gas emissions for flights, to/from airport transports, and energy use associated with accommodation at hotels were also calculated. The most comprehensive inventory data on chemicals use in the literature was introduced by this author and numerous aspects of the package holidays, more particularly flights, in which environmental improvements could be made, was highlighted.

\section{Energy audit in hotel buildings}

201 Some other studies focused only on energy and water consumption audits with no in-depth assessment of environmental effects associated with energy consumption in hotel buildings (Chan and Lam, 2002). Energy use profiles in 32 quality hotels in Antalya, Turkey (Önüt and Soner, 2006), 200 Mediterranean hotel units (Karagiorgas et al., 2006), and 36 quality hotels in Hong Kong (Deng and Burnett, 2000) were surveyed to examine the potential energy saving opportunities in building services installations. The findings from these studies indicate a diversified energy and water use in hotels, which considerably depend on a variety of parameters such as the year and type of construction, its location and climatic zone, the size and category of the hotel, the technology of heating, ventilation, and air conditioning (HVAC), the lighting systems, as well as the different building services and activities offered, amenities, and finally the occupancy rate.

Trung and Kumar (2005) took a wider approach as well, and evaluated Vietnamese tourism sector by performing an energy audit of hotel industry, through implementing questionnaires in 50 hotels. Inventory data on energy, water consumption, as well as the waste generated in Vietnamese hotels, was presented, however environmental consequences of accommodation services are not defined and measured in this study.

\section{Life Cycle Energy Analysis}

Despite plenty of applications of the LCA and Life Cycle Energy Analysis (LCEA), a simplified derivative of conventional LCA methodology, in the building sector, its use for environmental assessment of hotel buildings is scarce. A survey was conducted by Scheuer et al. (2003) to quantify the energy use and environmental impacts generated during the life cycle operations of a new university building with hotel functions in the USA. All impact categories that correlate closely with primary energy demand were measured. The HVAC, and electricity was highlighted as a significant aspect, which account nearly $95 \%$ of life cycle primary energy consumption of building. More recently König et al. (2007), performed a LCA to compare three alternative types of hotel building design in Portugal, in order to select the best option from an environmental point of view. To sum up, the existing literatures on energy audits and environmental assessments of the comercial and residential buildings, report that their total energy use is dominated by the operational energy consumption and therefore associated carbon footprint is the primary target for improving environmental impacts.

Filimonau et al. (2011) made some efforts to analyze the potential of a Life Cycle Energy Analysis (LCEA), to be utilized to assess the environmental performance of tourism accommodation facilities, and their contribution to global carbon footprint. LCEA was applied to two hotels in United Kingdom to calculate their contribution to global greenhouse gas emissions. Authors found that the operational carbon footprint of a hotel building is the critical aspect and predominantly associated with energy consumption in the form of heating, ventilation and air-conditioning, use of elevators, electric appliances and lighting in the building. These activities may account for up to $85 \%$ of the total energy use and especially in 
warm climates air-conditioning systems may increase the annual energy use by $29-77 \%$ depending on the type of the system (Santamouris et al., 1996). The results from studies indicate that LCEA has great potential for environmental assessment of hotels as it provides a quick and reliable insight in the hotel's energy consumption and easy-to-understand impact indicators that makes it a suitable decision-support instrument for hotel managers and policymakers.

Only a few studies have suggested a comprehensive analysis of energy use associated with an individual tourist's journey and dealt with the recreational component of the tourism (Becken and Patterson, 2006; Becken et al., 2003). Inventory data on energy use associated with different accommodation categories (hotels, bed and breakfast, backpacker, home, campground etc.) and different tourist attractions (shopping, visiting museums or art galleries, viewing wild life, taking scenic boat cruised etc.) by domestic and international tourists in New Zealand, was introduced by authors. The studies reveal that the main contributors within the attraction/activity category are water-borne motorized activities, such as scenic boat cruises, sea fishing and sailing, and air-borne activities, like heli-skiing and scenic flights. The contribution of tourist attractions, such as theme parks and buildings, to the overall energy demand is less important, because their management is easier and energy savings can be achieved with less effort, compared to the activity operators with fewer numbers of visitors, and a differentiated service level.

\section{Environmental impact of food consumption}

According to the literature (OECD, 2016) food and beverage consumption represents about $17 \%$ of domestic tourism total impact, while accommodation is about $18 \%$. Gössling et al. (2011) made an attempt to incorporate the climate change dimension of tourism-related food consumption that has not been covered in great depth in the tourism literature. A few studies have also focused in introducing food into the total ecological footprint of tourism at a particular destination, or in an individual hotel (Chambers, 2004; WWF-UK, 2002; Kuo et al 2005). Gössling et al. (2011) reviewed the carbon intensity of selected foods and analyzed the contribution of food production and consumption to global greenhouse gas emissions. Authors reported that managing foodstuff use in tourism related contexts, especially the ones that entail higher GHG emissions, could make a significant contribution to climate change mitigation. On the other side lack of reliable inventory data on the GHG intensity of foodstuffs and the complexity of food production chains are defined as the major drawbacks for the application of food management.

Despite extensive LCA studies are reported for other European countries, LCA has been rarely applied to Spanish tourism and limited research can be found on environmental assessment of hotels and tourism industry in Spain. Cadarso et al. (2015) carried out an inputoutput analysis with data from the input-output tables of Spanish tourism satellite accounts to quantify the national carbon footprint of Spanish tourism linked to tourism consumption.

Some authors focused on the environmental performance of hotels and several attempts were made in order to identify the processes that have the significant impact on the life cycle of the building (Moiá-Pol et al., 2005; Rosselló et al., 2008; Rosselló-Batle et al., 2010). The results show that the operating phase, representing the $70-80 \%$ of the total energy use, is the most significant contributor to energy use and associated $\mathrm{CO}_{2}$ emissions. Watson et al. (2009) drew attention to other sustainability tools in addition to environmental issues in order to 
investigate the sustainability of tourism in a more comprehensive manner. Authors conducted

291 a LCA, Life Cycle costing (LCC) and social LCA considering the visit of different types of tourists; residential, cruise ship and golf, to Majorca, which is the largest island of Balearic Islands and one of the most popular vacation destination in the world. Nevertheless, the results highlight the need of more comprehensive inventory data to complete the three parts of this sustainability analysis.

To sum up, existing literature on hotels and tourism industry in Spain deals with: a) aggregated data to quantify the total carbon footprint of Spanish tourism (Cadarso et al., 2016; Cadarso et al., 2015; Rosselló-Batle et al., 2010); b) LCA case studies analyzing environmental performance of hotel buildings (Rosselló et al., 2008; Rosselló-Batle et al., 2010); and c) a tourist visiting the Balearic Islands (Watson et al., 2009). In addition, these low numbers of LCA applications found in the literature do not provide any inventory data for Spanish hotels and its contribution to Global Warming Potential (GWP).

\section{Method}

The aim of the study was to identify the hotspots and contribute to inventory knowledge of accommodation services provided by coastland Spanish hotels for better environmental performance by applying a LCA framework in accordance with the guidelines and requirements of the (ISO 14044, 2006). This standard has four main steps: (1) goal and scope definition, (2) inventory analysis, (3) impact assessment and (4) interpretation of results.

Life cycle analysis (LCA) method was used to calculate the carbon footprint of Spanish hotels by assessing the GWP indicator expressed in $\mathrm{kg}$ of $\mathrm{CO}_{2}$-eq. Thus, carbon footprint is the indicator for one of the impact categories assessed in an LCA. Carbon Footprint may be assessed at product level (calculating the $\mathrm{CO}$ eq emissions of the product or service along its life cycle) following ISO 14067 (2013) or at corporate level (calculating CO2 eq emissions for a company during one year), following ISO 14064 (2006) standard (see Navarro, et al. 2017). In this study a product CF approach (following ISO 14067) will be performed to assess the accommodation service offered by hotels.

According to ISO 14067, the scope of the study and the functional unit have to be clearly identified and justified. The scope of the study and the main activities of the tourist accommodation within this scope are shown in Fig. 1. The functional unit is defined as "providing accommodation to a guest for an overnight stay". This is the most appropriate service oriented measure used by other authors that ensures the service offered corresponds to environmental efficiency (Cerutti et al., 2016, Chambers, 2004: Balázs et al., 2004: De Camillis et al., 2008: Raggi et al., 2005) and it is the best measure to use to enable comparisons between the performance of Spanish hotels with the performance of hotels in other regions.

The system boundaries of the present study don't include out-sourced laundry services and production of food for breakfast because no data was available from the hotels (Fig. 1). On the contrary, energy consumption and cleaning products related to in-sourced laundry services and breakfast are included because studied hotels had aggregated data on energy and chemicals consumption. Municipal waste production is considered in the inventory and its treatment is included in the carbon footprint calculation.

There is a common labeling system in Europe, the number of stars, to show the quality of a 
hotel. Thus, a $5^{*}$ hotel is a hotel of exceptional quality, service oriented, with $24 \mathrm{~h}$ roomservices, more than one restaurant and high quality facilities, usually offering additional sport and/or health services. On the other hand, a $2^{*}$ hotel offers a clean and basic accommodation with one restaurant offering just a coffee service and continental breakfast, with no additional services.

Life cycle inventory (LCI) data was collected from 14 coastland hotels located in Spain, through on-site surveys and environmental declarations of hotels in the framework of the SOSTUR Project ${ }^{1}$. The sample of hotels consists of two 2 stars, three 3 stars, six 4 stars and three 5 stars hotels. All of them are beach hotels and their number of room changes between 21 and 508. The hotels were chosen because of their location in the most representative beach touristic areas in Spain; their willingness to participate in the project, their participation in former projects and because they were able to provide the required input/output data from their activities (being inventory-data gathering usually the longest and most difficult task in an LCA study, authors wanted to be sure that the chosen hotels would provide accurate enough data). The studied hotels are not representative for coastland hotels in Spain, because higher number of hotels should be needed to be representative.

A questionnaire was prepared to collect inventory data from all sample hotels in the same conditions. Authors' previous experience in LCA and in hotels environmental management systems was used to prepare the questions (see Table 1). Some of the hotels accurately answered the questionnaires while others had to be asked for more detailed information and they sent different sources of information like bills, annual reports and other documents from which the authors obtained the necessary data to fill-in the questionnaire. The questionnaire was divided in 2 excel sheets: general aspects and hotel inventory (asking data about consumptions and emissions per 1 year time) (see Table 1). Visits to the hotels to help filling the questionnaire were performed, together with subsequent contacts through e-mail and phone calls to address the pending issues.

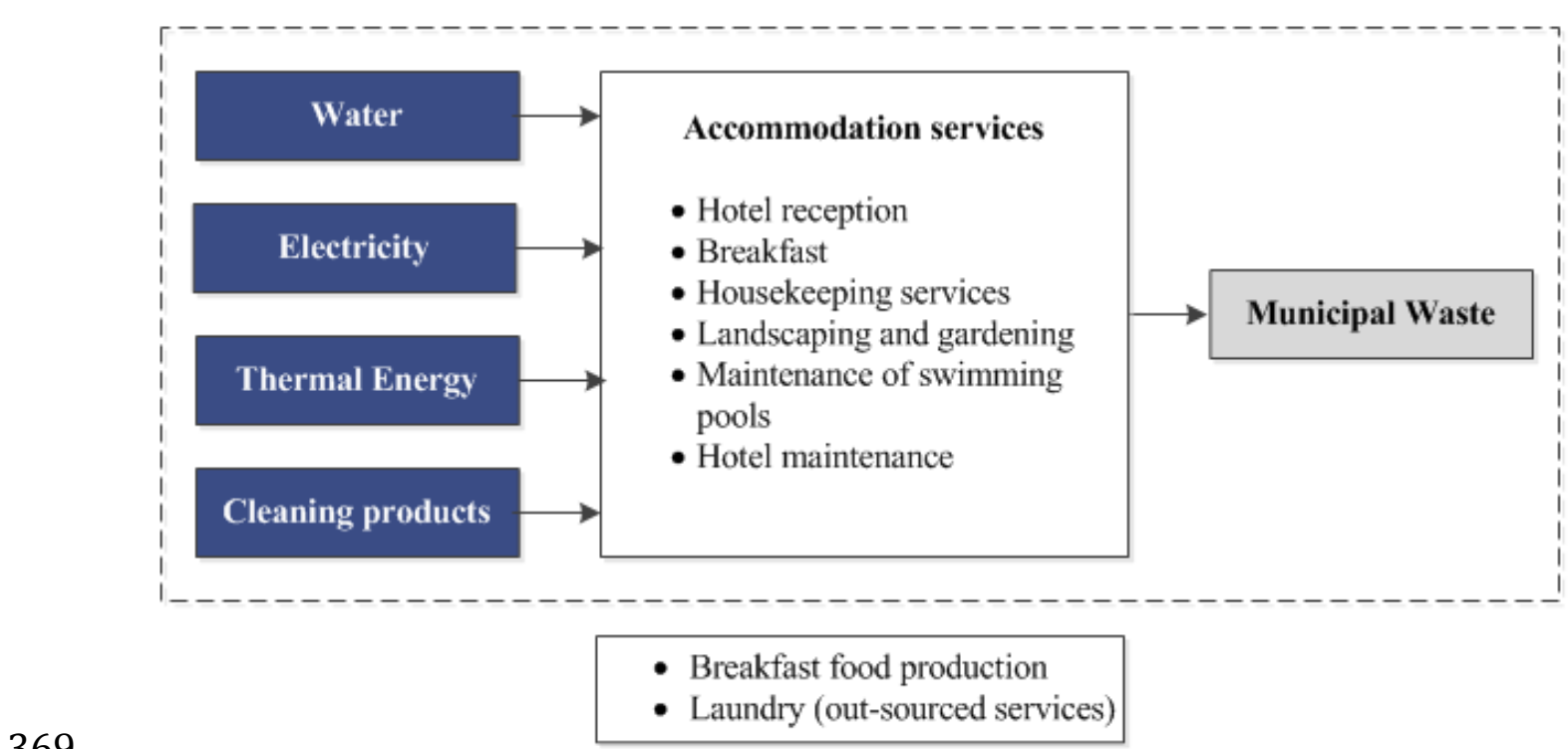

Fig. 1. System boundaries included in the study

\footnotetext{
${ }^{1}$ Research project to evaluate and improve the sustainability of the Andalusian tourism sector from a Life Cycle perspective. The aim of the project was to obtain inventory data for different tourism facilities and define the most convenient impact indicators for sustainability management of touristic areas in Andalusian region in Spain.
} 
Table 1. Type of information asked in the questionnaires.

\begin{tabular}{|c|c|c|}
\hline \multirow[t]{2}{*}{ General Aspects } & \multicolumn{2}{|c|}{ Hotel Inventory } \\
\hline & Consumptions & Waste \\
\hline Hotel name & Water $(\mathrm{kg})$ & Municipal solid waste $(\mathrm{kg})$ \\
\hline Address & Electricity $(\mathrm{kWh})$ & Plastics (kg) \\
\hline Year of data & Thermal energy (MJ) & Glass waste $(\mathrm{kg})$ \\
\hline Contact person & Type of fuel & Paper\&cardboard (kg) \\
\hline Number of rooms & Bleach/degreasing chemicals $(\mathrm{kg})$ & Vegetable oil $(\mathrm{kg})$ \\
\hline Services offered (room & Detergents, type and quantity $(\mathrm{kg})$ & Other wastes, type and quantity \\
\hline service, breakfast, lunch, & Disinfectants (kg) & $(\mathrm{kg})$ \\
\hline dinner, swimming-pool, & Lubricants (kg) & \\
\hline gardens, laundry, etc.) & Insecticides ( $\mathrm{kg}$ ) & \\
\hline & Swimming-pool chemicals $(\mathrm{kg})$ & \\
\hline Number of guest stay & Fertilizers, type and quantity $(\mathrm{kg})$ & \\
\hline Occupancy rate $(\%)$ & $\begin{array}{l}\text { Phytosanitary products, type and } \\
\text { quantity }(\mathrm{kg})\end{array}$ & \\
\hline
\end{tabular}

374

Average LCI data per hotel category was presented. Inventory results from the present study were compared with the ones shown in the literature for coastland hotels around the world.

GaBi 6 Software (Thinkstep, 2015) and databases included in this software (Thinkstep, ELCD, Ecoinvent and Plastics Europe) were used to build the system model and the environmental impact assessment used the CML 2001 methodology (CML, 2013). The global warming potential (GWP), excluding biogenic carbon, impact category described by Guinée et al. (2002) was used to calculate the carbon footprint indicator. Databases were necessary to have information on production processes for chemicals, fuels, electricity and water and for waste treatment processes.

Results of carbon footprint per functional unit were calculated per each studied hotel and the average impact and ranges per hotel category will be presented. The interpretation of the results obtained (both, inventory data and impact assessment results) will be discussed through section 4 .

\section{Life Cycle Inventory of the Spanish hotels}

\subsection{Description of hotels and inventory data results}

Life cycle inventory data regarding resource use and management for a period of 2000-2013 was gathered from sample hotels located in Catalunya, Balearic Islands and Valencia, which are among the most popular touristic coastal regions in Spain (Fig. 2). 


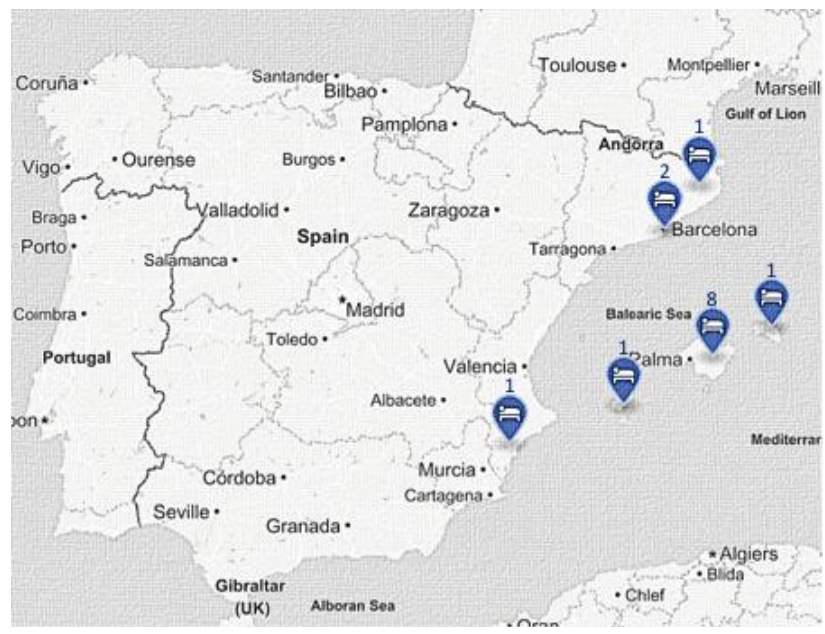

Fig. 2. Map of Spain showing the locations of sample coastland hotels under study.

The construction of the hotel buildings, the transportation and manufacturing of durable consumer goods and machinery were not included in the inventory data survey. Table 2 summarizes some of the general characteristics of the hotels under study. Some characteristics, especially the period of operational season and the size of green areas surrounding the hotel building demonstrate a wide range of variation. In table 2, some data are missing because, although authors tried, hotels didn't have or didn't report them. Nevertheless, missing data was not very important for the study, unless data on occupancy rate which was identified later to be very important, but some hotels didn't had this information.

Table 2. General characteristics of Spanish hotels under study

\begin{tabular}{|c|c|c|c|c|c|c|c|c|}
\hline Location & $\begin{array}{c}\text { Operational } \\
\text { season } \\
\text { (months) }\end{array}$ & $\begin{array}{l}\text { Number of } \\
\text { hotel rooms }\end{array}$ & $\begin{array}{l}\text { Overnight } \\
\text { stay }\end{array}$ & $\begin{array}{l}\text { Occupancy } \\
\text { rate }(\%)\end{array}$ & $\begin{array}{c}\text { Green } \\
\text { area } \\
{\left[\mathbf{m}^{2}\right]}\end{array}$ & $\begin{array}{c}\text { Built up } \\
\text { area } \\
{\left[\mathrm{m}^{2}\right]}\end{array}$ & $\begin{array}{c}\text { Number of } \\
\text { swimming } \\
\text { pools }\end{array}$ & $\begin{array}{c}\text { Laundry } \\
\text { service }\end{array}$ \\
\hline \multicolumn{9}{|l|}{ 5-Star } \\
\hline Majorca & 12 & 174 & 52805 & 42.3 & - & 17800 & 3 & \multirow{3}{*}{$\begin{array}{c}\text { Outsourced } \\
\text { Out- and } \\
\text { insourced } \\
\text { Outsourced }\end{array}$} \\
\hline Majorca & - & 114 & 30054 & - & - & 13037 & 2 & \\
\hline Majorca & 8 & 236 & 47521 & - & - & - & 2 & \\
\hline \multicolumn{9}{|l|}{ 4-Star } \\
\hline Majorca & 6 & 508 & 173126.4 & 71 & 72250 & 12750 & 3 & \multirow{5}{*}{$\begin{array}{c}\text { Outsourced } \\
\text { Out- and } \\
\text { insourced } \\
\text { Outsourced } \\
\text { Outsourced } \\
\text { Out- and } \\
\text { insourced } \\
\text { Not } \\
\text { specified }\end{array}$} \\
\hline Barcelona & 12 & 314 & 167562 & 90.5 & - & 19904 & & \\
\hline $\begin{array}{l}\text { Majorca } \\
\text { Maiorca }\end{array}$ & $\begin{array}{l}12 \\
12\end{array}$ & $\begin{array}{l}340 \\
204\end{array}$ & $\begin{array}{c}198200 \\
93048\end{array}$ & $\begin{array}{c}95 \\
100\end{array}$ & $\begin{array}{l}2800 \\
2400\end{array}$ & $\begin{array}{c}- \\
4576\end{array}$ & $\begin{array}{l}2 \\
2\end{array}$ & \\
\hline Minorca & 6 & 346 & 121000 & 100 & 0 & 15250 & 2 & \\
\hline Barcelona & 12 & 108 & 49272 & - & 0 & 4678 & & \\
\hline \multicolumn{9}{|l|}{ 3-Star } \\
\hline Alicante & 12 & 794 & 577094 & 95.07 & - & 25317 & 3 & \multirow{3}{*}{$\begin{array}{c}\text { Not } \\
\text { specified } \\
\text { Out- and } \\
\text { insourced } \\
\text { Outsourced }\end{array}$} \\
\hline Ibiza & 9 & 291 & 130987 & 85 & 200 & - & 2 & \\
\hline Majorca & 9 & 273 & 100435 & - & - & - & 2 & \\
\hline \multicolumn{9}{|l|}{ 2-Star } \\
\hline Girona & 7 & 84 & 26123 & - & - & - & 1 & \multirow{2}{*}{$\begin{array}{c}\text { Out- and } \\
\text { insourced } \\
\text { Not } \\
\text { specified }\end{array}$} \\
\hline Majorca & 12 & 21 & 2200 & 25 & - & - & 1 & \\
\hline
\end{tabular}


Most of the 4 and 5 star hotels are not equipped with laundries; the service is outsourced in order to minimize operating costs. All of the sample hotels are equipped with kitchen as all of them provide breakfast, and even it is not a complete menu most of them offer dinner too.

In order to evaluate the environmental improvement of hotels by a voluntary implementation of environmental monitoring systems (EMAS regulation), for three hotels, data from a prior period of more than five years were also included in the inventory (same hotel without and with implementation of EMAS regulation). Recent and anterior inventory data regarding one of the sample hotels is shown in section 4.3 (see Table 5). EMAS regulation is the EU EcoManagement and Audit Scheme (EMAS, 2009), a premium management instrument developed by the European Commission for companies and other organizations to evaluate, report, and improve their environmental performance. It is an environmental management system similar to ISO 14001 .

Average inventory data for 17 data sets considered in the study are given in Table 3. A great number and variety of cleaning products were reported by the hotels, such as bleaches, disinfectants, shower cream, soap, shampoo, liquid and powder detergents, etc., which resulted in difficulties in categorization of these products. To overcome this issue cleaning chemicals have been characterized in 5 types: chlorine and ammonia derivatives, degreasing agents, laundry detergents and others. After calculating their associated impact they are presented just as one single type (see Table 3): cleaning products, due to the low amount used and great variation among hotels.

Table 3. Average inventory data (per overnight stay) for Spanish hotels according to their star category

\begin{tabular}{|c|c|c|c|c|}
\hline & Hotel 5* & Hotel 4* & Hotel 3* & Hotel 2* \\
\hline Number of guest stay per year & 39301 & 148367 & 232369 & 14161 \\
\hline Occupancy rate $(\%)$ & 50 & $90-100$ & $85-95$ & 30 \\
\hline Location & Majorca & $\begin{array}{l}\text { Barcelona- } \\
\text { Majorca }\end{array}$ & $\begin{array}{l}\text { Alicante- } \\
\text { Balearic Islands }\end{array}$ & $\begin{array}{l}\text { Gerona- } \\
\text { Majorca }\end{array}$ \\
\hline \multicolumn{5}{|l|}{ Consumption } \\
\hline Water $\left[\mathrm{m}^{3} /\right.$ overnight stay] & 0.58 & 0.32 & 0.19 & 0.54 \\
\hline Electricity [kWh/overnight stay] & 30 & 11 & 6.2 & 29 \\
\hline $\begin{array}{l}\text { Energy sources (fuels for thermal energy) } \\
\text { [MJ/overnight stay] }\end{array}$ & 95 & 71 & 24 & 127 \\
\hline Cleaning products [kg/overnight stay] & 0.43 & 0.43 & 0.43 & 0.43 \\
\hline \multicolumn{5}{|l|}{ Waste } \\
\hline Municipal solid waste [kg/overnight stay] & 1.93 & 1.93 & 1.93 & 1.93 \\
\hline Vegetable oil [L/overnight stay] & 0.012 & 0.012 & 0.012 & 0.012 \\
\hline Waste water [L/overnight stay] & 577 & 320 & 190 & 536 \\
\hline
\end{tabular}


As can be seen from Table 3, water and electricity consumption is highest in 5 star hotels, while in 3 star categories is lowest. Differences in energy consumption performance are significantly affected by geographical location, energy installations, operating schemes and by the fact that most of the hotels located in islands are not fully functioning all year. Fuels consumed are diesel and natural gas (for heating) and propane (mainly for the kitchen). The average electricity and water consumption per overnight stay for 2 and 5 star hotels are similar. Although this may be due to inefficiency for the 2-star hotels and multiplicity of services for the 5-star ones, this point should be further investigated in future works considering more detailed inventory data from more hotels.

Total energy use is slightly dominated by electricity consumption in 5 star hotels, while thermal energy consumption from fuels is higher in the other hotel categories, especially in 4 star hotels (See Fig. 3). Energy sources are mainly for heating, cooking, lighting and air conditioning. Santamouris et al. (1996) reported that air-conditioning systems may increase the annual energy use up to $77 \%$ which is probably also the case in this study as the hotels analyzed in this study are concentrated in coastal areas, and most of them are located in Balearic Islands where the weather is hot in summer (about $30^{\circ} \mathrm{C}$ ) and warm during the whole year except for winter $\left(5-9^{\circ} \mathrm{C}\right)$, but most hotels are closed during winter time.

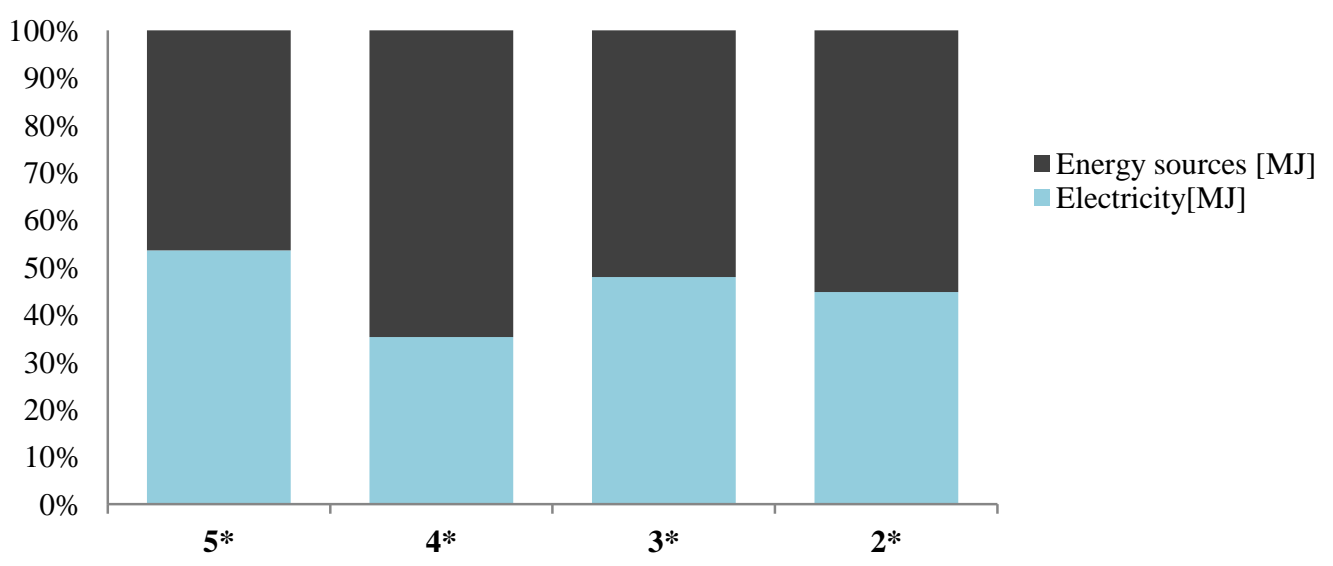

Fig. 3. Energy use pattern for each hotel category.

The waste flows are mainly composed by office materials (paper, cardboard, cartridges etc.), packing materials, batteries, used vegetable oil, and municipal solid waste. Unfortunately, waste inventory data (type and quantity) is not well audited and documented by hotels. In this respect, only municipal solid waste and vegetable oil waste were considered in the waste category, because these were the ones most commonly reported. In respect of inventory data for cleaning products and waste per overnight stay, the average values were taken from 4 star hotels, as detailed data for different types of accommodation were not available and they reported comparatively much more complete and detailed data.

\subsection{Comparison with other published studies}

As previously mentioned, scarce literature reports inventory data for coastland hotels around the world and, when reported, only electricity and water consumption data is usually found. Table 4 compares the average of Spanish hotels in our study for electricity and water 
consumption with respect to the mean values, reported in the literature for Asian and European hotels (Castellani and Sala, 2012; Trung and Kumar, 2005). Data on energy and water performance for 5-star hotel category in Asia were taken from resort hotels in Vietnam, because no 5-star category was reported.

Table 4. Inventory data taken from different published studies.

\begin{tabular}{|c|c|c|c|c|c|c|}
\hline \multirow[t]{3}{*}{ Hotel category } & \multicolumn{3}{|c|}{$\begin{array}{c}\text { Energy performance } \\
\text { kwh electricity/overnight stay }\end{array}$} & \multicolumn{3}{|c|}{$\begin{array}{c}\text { Water performance } \\
\mathrm{m}^{3} \text { water/overnight stay }\end{array}$} \\
\hline & \multicolumn{3}{|c|}{ Reference data } & \multicolumn{3}{|c|}{ Reference data } \\
\hline & Spanish* & Asian & European & Spanish* & Asian & European \\
\hline \multicolumn{7}{|l|}{ 5-star } \\
\hline & 30 & $18-24^{\mathrm{a}}$ & $33.4^{\mathrm{c}}$ & 0.58 & $6.3-19.6^{\mathrm{a}}$ & $0.31^{\mathrm{c}}$ \\
\hline \multicolumn{7}{|l|}{ 4-star } \\
\hline & 11 & $24-43^{\mathrm{a}}$ & $\begin{array}{l}21.8^{\mathrm{b}} \\
33.7^{\mathrm{c}}\end{array}$ & 0.32 & $1.2-1.5^{\mathrm{a}}$ & $0.2^{\mathrm{c}}$ \\
\hline
\end{tabular}

3-star

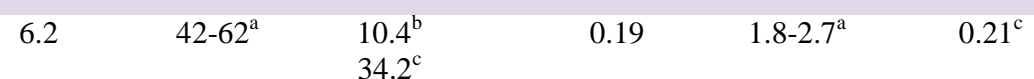

\section{2-star}

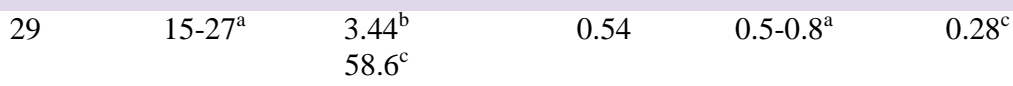

* Our study, ${ }^{\mathrm{a}}$ (Trung and Kumar, 2005), ${ }^{\mathrm{b}}\left(\right.$ Castellani and Sala, 2012), ${ }^{\mathrm{c}}($ SUTOUR, 2007)

Table 4 shows that, when compared with Asian hotels for specific electricity and water consumption, 4 and 3-star Spanish hotels have significantly lower consumption while 2-star hotels have similar figures. When compared with European coastland hotels, Spanish 4 and 3star ones have similar water consumption and slightly lower electricity use.

Finally, although 5-star Spanish hotels have significantly lower water consumption in comparison to Asian resort hotels, their performance is similar to those reported by European hotels.

In general, Asian hotels reported higher energy and water consumption values in comparison with the European ones. Inventory data from Asian hotels are significantly older than for European hotels, and considering the differing geographies; climates and technological developments adopted by European hotels, the complexity of comparison and interpretation of data can be considered as challenging.

The average data regarding waste generation (1.93 $\mathrm{kg}$ waste/overnight stay) is well aligned with previously published data for the Balearic Islands, which is $1.55 \mathrm{~kg}$ waste/overnight stay (Rosselló-Batle et al., 2010).

\subsection{Some factors affecting the variability of inventory data}

A broad range of variation in resource consumption for each hotel category was observed. One of the main reasons of variation in inventory data is the different occupation rates. As can be seen from Fig. 4 and Fig. 5, not surprisingly, the overnight stay consumption of both water and electricity decreases by increasing occupancy rate or the other way around, for the 
non-variable consumption is distributed among more or less stays. This is consistent with the

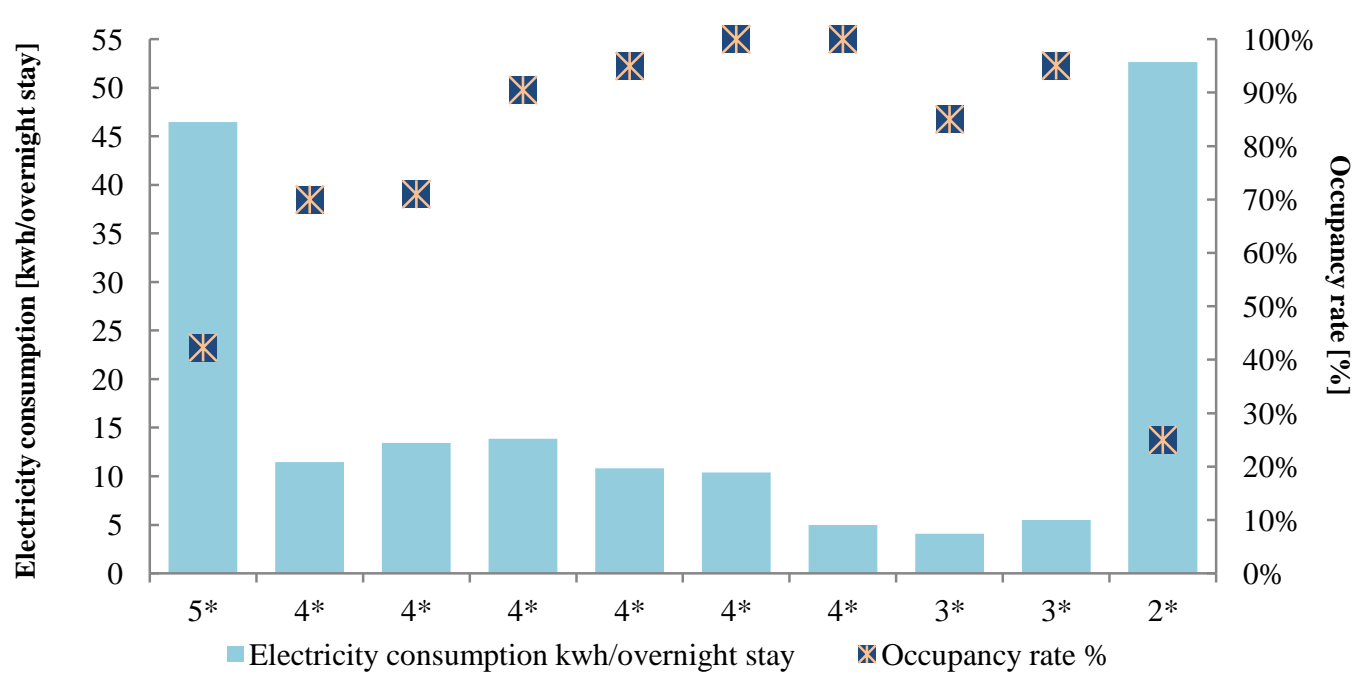

Fig. 4. Effect of occupancy rate on electricity consumption.

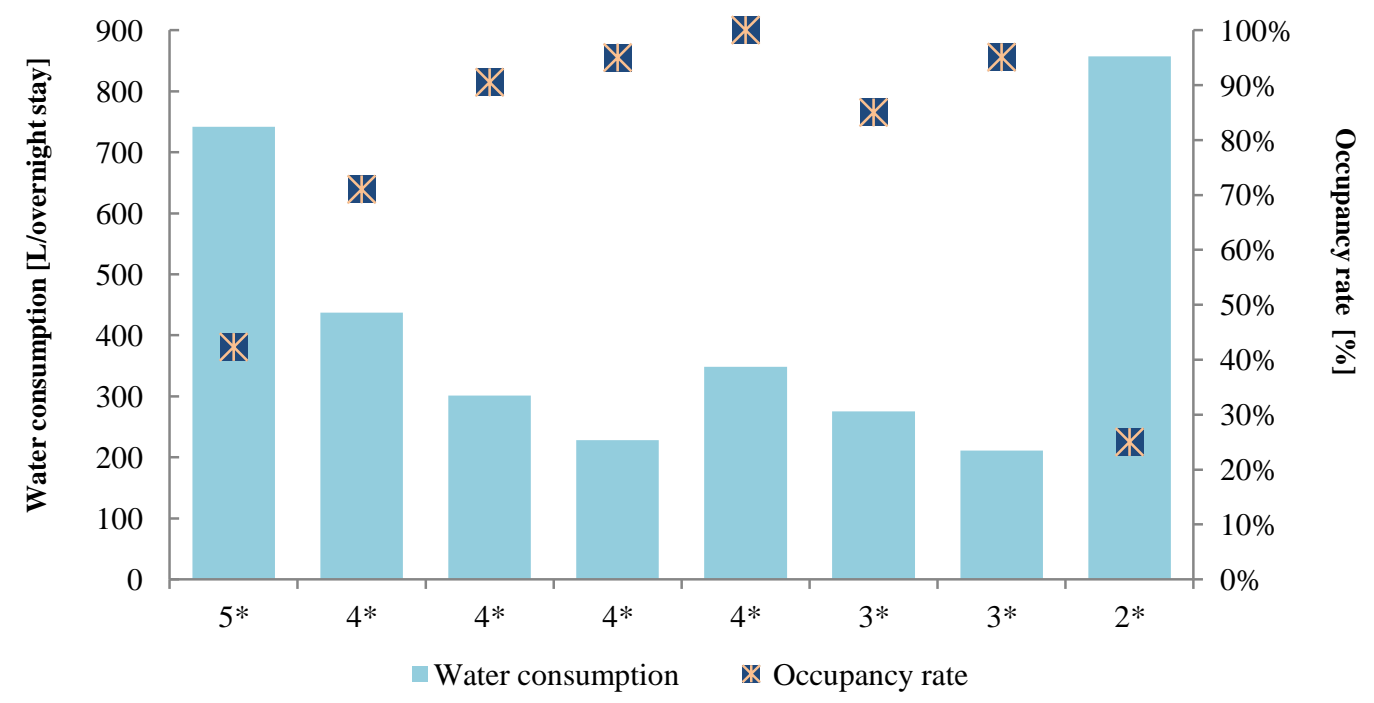

Fig. 5. Effect of occupancy rate on water consumption.

The diversity of facilities and services provided by hotels also has a significant effect on energy consumption variation. Diverse green areas surrounding hotel building, number of swimming pools, and whether the hotels are equipped with laundry or contract this service to outside laundry facilities are other reasons for inventory data diversity. Among the 4-star hotels, the ones with the largest green areas have the highest water consumption, due to maintenance of gardens and landscaping activities. Different energy consumption pattern of hotels, also contributes to variability of inventory data. Electricity dominates the energy consumption of 5-star hotels, where it accounts nearly 55\% of their total energy use (see Fig. 

represents more than 50\% of total energy consumption (Bohdanowicz and Martinac, 2007; Rosselló-Batle et al., 2010). On the other hand, 4-star hotels rely more on other sources such as diesel and natural gas that correspond almost to $70 \%$ of their energy use.

In order to evaluate the effect of voluntary implementation of environmental monitoring systems (EMAS) on resource consumption profile of hotel, recent and anterior inventory data regarding one of the sample hotels was given as example in Table 5. Hotels with longer experience of environmental monitoring and eco-management (EMAS) reported more detailed and accurate inventory data, which eventually leads to implement environmental improvement strategies within the hotel. They apply various measures, such as establishment of ecobilling (a computer program that sends bills online) and improving energy and water efficiency in order to diminish resource consumption. Some of these measures were already recommended in previous literature (Cadarso et al., 2016; De Camillis et al., 2010)

Table 5. Comparative inventory data of a sample hotel from two operational seasons

\begin{tabular}{|c|c|c|}
\hline & $\begin{array}{l}\text { Without EMAS } \\
\text { experience }\end{array}$ & $\begin{array}{l}\text { With EMAS } \\
\text { experience }\end{array}$ \\
\hline & Hotel 4* & Hotel 4* \\
\hline Number of guest stay per year & 75713000 & 76194000 \\
\hline Occupancy rate $(\%)$ & $71 \%$ & $72 \%$ \\
\hline Location & Majorca & Majorca \\
\hline \multicolumn{3}{|l|}{ Consumption [per overnight stay] } \\
\hline Water [L] & 437.32 & 322.36 \\
\hline Electricity $[\mathrm{kWh}]$ & 13.44 & 10.49 \\
\hline \multicolumn{3}{|l|}{ Energy sources (fuels for thermal energy) } \\
\hline Propane $[\mathrm{kg}]$ & 0.05 & 0.15 \\
\hline Diesel [L] & 1.107 & 0.62 \\
\hline \multicolumn{3}{|l|}{ Cleaning and maintenance products [per overnight stay] } \\
\hline Bleach/degreasing chemicals [L] & 0.013 & 0.013 \\
\hline Dish washing detergent $[\mathrm{kg}]$ & 0.046 & 0.02 \\
\hline Cleaning chemicals for general purpose $[\mathrm{kg}]$ & 0.002 & 0.001 \\
\hline Disinfectants $[\mathrm{L}]$ & 0.0096 & 0.005 \\
\hline Insecticides [kg] & - & 0.005 \\
\hline Lubricants/grease $[\mathrm{kg}]$ & - & 0.00003 \\
\hline Washing detergents $[\mathrm{kg}]$ & 0.00006 & 0.0354 \\
\hline Pool disinfectants $[\mathrm{kg}]$ & - & 0.143 \\
\hline Fertilizers $[\mathrm{kg}]$ & - & 0.00019 \\
\hline Phytosanitary products $[\mathrm{kg}]$ & - & 0.00162 \\
\hline \multicolumn{3}{|l|}{ Waste [per overnight stay] } \\
\hline Municipal solid waste [kg] & 2.49 & 1.49 \\
\hline Plastics [kg] & - & 0.054 \\
\hline Glass $[\mathrm{kg}]$ & 0.369 & 0.33 \\
\hline Cartridges, toner [kg] & 0.00026 & 0.0002 \\
\hline Vegetable oil [L] & 0.013 & 0.016 \\
\hline
\end{tabular}

However, hotels without eco-management do not declare any data in some categories and 561 would appear to have a better environmental performance due to lack of input data. In our 
case, this applies both for inventory data regarding types and quantities of waste discharged, and products consumed for cleaning purposes. To avoid this problem, for such hotels, default values should be provided in following studies (coming from wider hotel samples and more detailed inventory data) to push such under-reporting hotels to monitor, audit and provide their own data so to overcome the actual identified distorting picture.

Going more in depth with the analysis is unfeasible at this moment due to aggregated data provided by some of the sample hotels. On the other hand, considering the improvement of inventory data quality provided by hotels involved in EMAS systems, it is expected to obtain in the near future more detailed inventory information from great majority of hotels. This will lead to more accurate approach, more detailed recommendations for the mitigation of carbon footprint and eventually will ensure implementation of more precise policy making from a wider perspective.

\subsection{Calculation of Carbon footprint}

The associated greenhouse gas (GHG) emissions from energy, water and resource consumptions, as well as from generation of waste, were calculated in $\mathrm{kg} \mathrm{CO}_{2}$-eq per overnight stay using the average data given in Table 2 (see Fig. 6). For $\mathrm{CO}_{2}$ emissions accounting, the emission factors of each energy source and waste treatment considered in the analysis were taken from IPCC 2007. They were calculated according to country and region specific characteristics (OCCC, 2015). Emission factors for cleaning products and others, were taken from the GaBi6 professional database (Thinkstep, 2015). Results of environmental impact are presented in Fig. 6. Total carbon footprint of 2-star hotels has the highest carbon emissions value, followed by 5 and 4-star hotel categories, respectively, with 23, 22 and 12 $\mathrm{kg} \mathrm{CO}$-eq/overnight stay, which follows the same rule described above of being inversely proportional to the occupancy rate. 


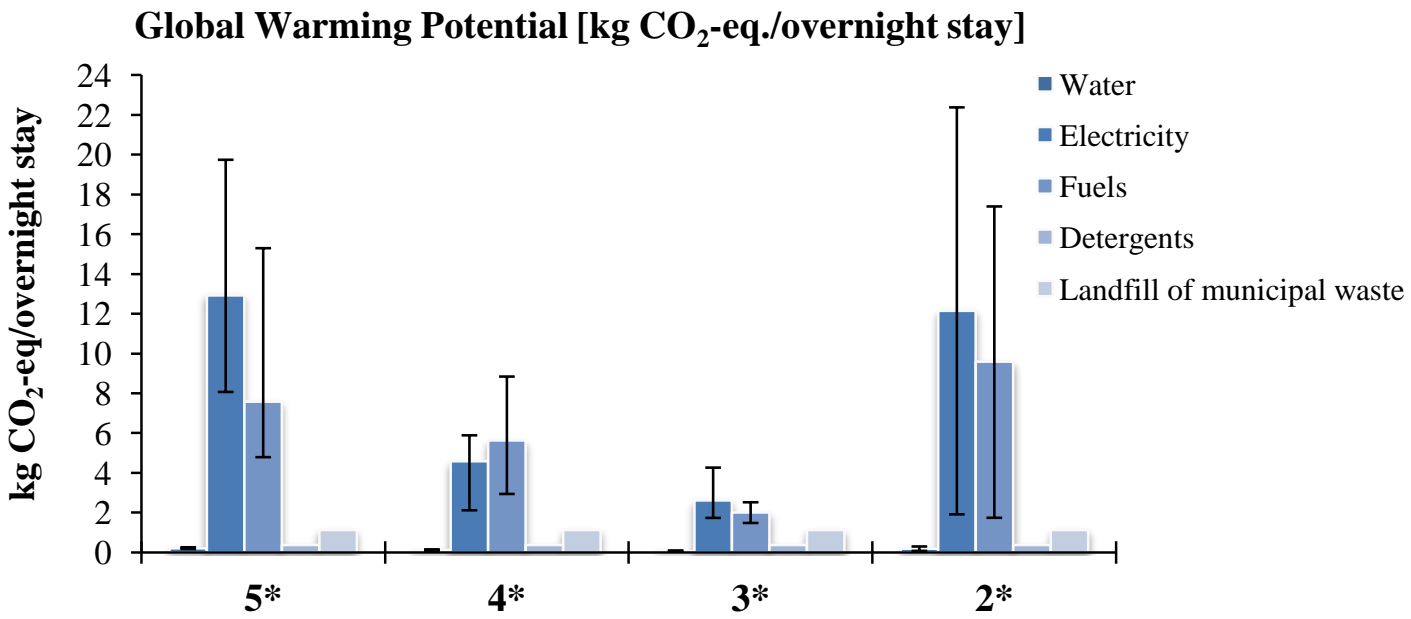

Fig. 6. Contribution of primary consumptions to overall hotel carbon footprint.

Error bars in Fig. 6 present the minimum and maximum carbon emission values within each hotel category. A comparatively larger variation exists in carbon emissions associated with 5 and 2-star hotels, where sample hotels of low occupancy rate were presented. The $\mathrm{CO}_{2}$ emission values from 4-star hotels (that provided more detailed and accurate inventory data) show a much lower variation.

Water consumption has a very small average contribution of about $1 \%$ within each hotel category. The use of fuels makes the highest contribution to 4-star hotels being responsible for $48 \%$ of overall carbon emissions, while the highest contributor within the other hotel categories is electricity. GHGs associated with production of cleaning products and management of municipal waste have the highest share in 3 star hotels with $6 \%$ and $18 \%$ respectively.

\section{Conclusions}

In this preliminary research life cycle perspective was applied for environmental evaluation of 14 Spanish coastland hotels to quantify their contribution to global GHG emissions and highlight the processes and flows that have the highest resource consumption and highest environmental burden. Based on findings from the study, average inventory data for inputs and outputs of Spanish-coastland-hotel-services related with different star categories were proposed. A cause-effect analysis for data variability was performed, finding that the hotel occupancy rate is the most affecting factor for data variability and that 5 and 2-star hotels are the categories with more variability of inputs and outputs per overnight stay.

The results show that 2-star hotels have the highest carbon emissions values followed by 5 and 4-star hotel categories. Energy and water consumption are proportional to the number of stars and the occupancy rate. Given that energy use is closely linked to GHG emissions, adopting energy saving measures and a convenient share of energy sources would be a primary opportunity to promote sustainable consumption patterns in Spanish hotels. 
It is revealed that voluntary implementation of environmental monitoring systems (ie. EMAS regulation) promotes collection of detailed and accurate inventory data, which facilitates mitigation of resource use through the establishment of best practices within the hotel. Therefore, accurate inventory data collection is not a whim, but a necessary step to reduce the impacts of the sector.

The exponential growth of the global tourism sector, its consumption and level of impacts on the environment, needs an urgent response and tourism related stakeholders and managers need to have decision making tools to lead tourism to a sustainable private sector. This decision-making tools and system models have to be filled-in with inventory data from different tourist services (ie. accommodation) to calculate sustainability key indicators, which can lead to achieve real sustainable goals.

To improve the environmental profile of the tourism sector, existing companies and tourism entrepreneurs should be aware of their responsibility for the overall impacts generated by tourism activities. Given that their activity relies mainly on environmental resources, they should consider taking a more proactive step into sustainable decision-making as well. Proposed default inventory data will be useful for tourism related managers: destination managers, policy makers and hotel managers among others.

Although the present paper already contributes to the goal of providing inventory data for Spanish hotels for the first time, data collection should be expanded in future projects by gathering data from more hotels, other accommodation facilities and also other products/services offered by tourist sector in Spain (like transport of tourists, laundry, food and beverage, culture-sports \& recreation and others).

\section{Acknowledgements}

This study has been developed in the framework of SOSTUR, a project coordinated by IAT; financed by the Consejería de Economía, Innovación, Ciencia y Empleo of Junta de Andalucía (Regional Government of Andalusia) and with Cyclus Vitae Solutions,S.L. and UNESCO Chair in Life Cycle and Climate Change (ESCI-UPF) as partners.

The authors are responsible for the choice and presentation of information contained in this paper as well as for the opinions expressed therein, which are not necessarily those of UNESCO and do not commit this Organization.

\section{References}

Bala, A., Raugei, M., Benveniste, G., Gazulla, C., Fullana-i-Palmer, P., 2010. Simplified tools for global warming potential evaluation: when 'good enough' is best. International Journal of Life Cycle Assessment 15, 489-498.

677 Balázs, S., Raggi, A., Petti, L., Scimìa, E., 2004. Implementation of LCA to services: case studies in 678 the hospitality industry, Sixth International Conference on EcoBalance, Tsukuba, Japan, pp. 127-128.

679 Becken, S., Patterson, M., 2006. Measuring National Carbon Dioxide Emissions from Tourism as a 680 Key Step Towards Achieving Sustainable Tourism. Journal of Sustainable Tourism 14, 323-338.

681 Becken, S., Simmons, D.G., Frampton, C., 2003. Energy use associated with different travel choices. 682 Tourism Management 24, 267-277. 

sustainability indicators for tourism planning: The case of rural tourism in Andalusia (Spain). Science of the Total Environment 412-413, 28-45.

686 Bohdanowicz, P., Martinac, I., 2007. Determinants and benchmarking of resource consumption in hotels - Case study of Hilton International and Scandic in Europe. Energ Buildings 39, 82-95.

Cadarso, M.Á., Gómez, N., López, L.A., Tobarra, M.Á., 2016. Calculating tourism's carbon footprint: measuring the impact of investments. Journal of Cleaner Production 111, 529-537.

Cadarso, M.Á., Gómez, N., López, L.A., Tobarra, M.Á., Zafrilla, J.E., 2015. Quantifying Spanish tourism's carbon footprint: the contributions of residents and visitors. A longitudinal study. Journal of Sustainable Tourism 23, 922-946.

693 Castellani, V., Sala, S., 2012. Ecological Footprint and Life Cycle Assessment in the sustainability assessment of tourism activities. Ecological Indicators 16, 135-147.

Cerutti, A., Beccaro, G., Bruun, S., Donno, D., Bonvegna, L., Bounous, G., 2016. Assessment methods for sustainable tourism declarations: the case of holiday farms. Journal of Cleaner Production 111, 511 519.

Chambers, T., 2004. Environmental Assessment of a mass tourism package holiday and a responsible tourism package holiday, using Life Cycle Assessment and Ecological Footprint Analysis, Environmental Sciences. University of East Anglia, Norwich, UK.

Chan, W.W., Lam, J.C., 2002. Prediction of pollutant emission through electricity consumption by the hotel industry in Hong Kong. International Journal of Hospitality Management 21, 381-391.

CML, 2013. CML-IA Characterisation Factors. Update information version 4.2, released april 2013.

http://cml.leiden.edu/software/data-cmlia.html - downloads.

De Camillis, C., Petti, L., Raggi, A., 2008. LCA: a key-tool for Sustainable Tourism?, Eighth International Conference on EcoBalance, Tokyo, Japan, pp. pp. 485-488.

De Camillis, C., Raggi, A., Petti, L., 2010. Life Cycle Assessment in the framework of sustainable tourism: a preliminary examination of its effectiveness and challenges. Progress in Industrial Ecology An International Journal 7, 205-218.

710 Deng, S.M., Burnett, J., 2000. A study of energy performance of hotel buildings in Hong Kong. Energ 711 Buildings 31, 7-12.

712 El Hanandeh, A., 2013. Quantifying the carbon footprint of religious tourism: the case of Hajj. Journal 713 of Cleaner Production 52, 53-60.

714 EMAS, 2009. Regulation (EC) No 1221/200 of the european parliament and of the council of 25 715 November, 2009, on the voluntary participation by organisations in a Community eco-management and 716 audit scheme (EMAS).

Filimonau, V., Dickinson, J., Robbins, D., 2014. The carbon impact of short-haul tourism: a case study of UK travel to Southern France using life cycle analysis. Journal of Cleaner Production 64, 628-638.

Filimonau, V., Dickinson, J., Robbins, D., Huijbregts, M.A.J., 2011. Reviewing the carbon footprint analysis of hotels: Life Cycle Energy Analysis (LCEA) as a holistic method for carbon impact appraisal of tourist accommodation. Journal of Cleaner Production 19, 1917-1930.

Filimonau, V., Dickinson, J., Robbins, D., Reddy, M.V., 2013. The role of 'indirect' greenhouse gas emissions in tourism: Assessing the hidden carbon impacts from a holiday package tour. Transportation Research Part A: Policy and Practice 54, 78-91.

Fullana-i-Palmer, P., Puig, R., Bala, A., Baquero, G., Riba, J., Raugei, M., 2011. From Life Cycle

727 Assessment to Life Cycle Management A Case Study on Industrial Waste Management Policy Making. $728 \mathrm{~J}$ Ind Ecol 15, 458-475.

729 Gössling, S., Garrod, B., Aall, C., Hille, J., Peeters, P., 2011. Food management in tourism: Reducing tourism's carbon 'foodprint'. Tourism Management 32, 534-543. 

Suh, S., Udo de Haes, H.A., de Bruijn, H., van Duin, R., Huijbregts, M.A.J., 2002. Life Cycle Assessment: an Operational Guide to the ISO Standards. Kluwer Academic Publishers, Dordrecht, NL.

Hu, A., Huang, C., Chen, C., Kuo, C., Hsu, C., 2015. Assessing carbon footprint in the life cycle of accommodation services: the case of an international tourist hotel. International Journal of Sustainable Development \& World Ecology 22, 313-323.

IPCC, 2007. Climate Change 2007: Mitigation. Contribution of Working Group III to the Fourth Assessment Report of the Intergovernmental Panel on Climate Change. Cambridge University Press, , Cambridge, United Kingdom and New York, NY, USA.

740 ISO 14044, 2006. ISO 14044 Environmental Management e Life Cycle Assessment e Requirements 741 and Guidelines.

742 ISO 14064, 2006. ISO 14064-1:2006: Greenhouse gases -- Part 1: Specification with guidance at the organization level for quantification and reporting of greenhouse gas emissions and removals. International Organization for Standardization, Geneva, Switzerland.

ISO 14067, 2013. ISO/TS 14067: Greenhouse gases - Carbon footprint of products - Requirements and guidelines for quantification and communication, International Organization for Standardization.

Karagiorgas, M., Tsoutsos, T., Drosou, V., Pouffary, S., Pagano, T., Lara, G., Melimmendes, J., 2006. HOTRES: renewable energies in the hotels. An extensive technical tool for the hotel industry. Renewable and Sustainable Energy Reviews 10, 198-224.

Köberl, J., Prettenthaler, F., Bird, D., 2016. Modelling climate change impacts on tourism demand: A comparative study from Sardinia (Italy) and Cap Bon (Tunisia). Science of The Total Environment 543, 1039-1053.

König, H., Schmidberger, E., De Cristofaro, L., 2007. Life cycle assessment of a tourism resort with renewable materials and traditional construction techniques., Portugal SB07, Sustainable construction, materials and practices. IOS Press, Amsterdam.

Kuo, N.-W., Chen, P.-H., 2009. Quantifying energy use, carbon dioxide emission, and other environmental loads from island tourism based on a life cycle assessment approach. Journal of Cleaner Production 17, 1324-1330.

Kuo, N.W., Hsiao, T.Y., Lan, C.F., 2005. Tourism management and industrial ecology: a case study of food service in Taiwan. Tourism Management 2, 503-508.

761 Michailidou, A., Vlachokostas, C., Moussiopoulos, N., Maleka, D., 2016. Life Cycle Thinking used for assessing the environmental impacts of tourism activity for a Greek tourism destination. Journal of Cleaner Production 111, 499-510.

Michailidou, A.V., Vlachokostas, C., Moussiopoulos, N., 2015. A methodology to assess the overall environmental pressure attributed to tourism areas: A combined approach for typical all-sized hotels in Chalkidiki, Greece. Ecological Indicators 50, 108-119.

Moiá-Pol, A., M. Karagiorgas, D. Coll-Mayor, V. Martínez-Moll, Riba-Romeva, C., 2005. Evaluation of the energy consumption in Mediterranean islands hotels: Case study: The Balearic islands hotels, The International Conference on Renewable 267 Energies and Power Quality (ICREPQ 05), Zaragoza, Spain.

Navarro, A., Puig, R., Fullana-i-Palmer, P. 2017. Product vs corporate carbon footprint: Some methodological issues. A case study and review on the wine sector, Sci Total Environ (2017), in press. http://dx.doi.org/10.1016/j.scitotenv.2016.12.190

OCCC, 2015. Oficina Catalana del Canvi Climàtic, Guia pràctica per al càlcul d'emissions de gasos amb efecte d'hivernacle (GEH).

\section{OECD, 2016. OECD Tourism trends and policies 2016. Highlights}

Önüt, S., Soner, S., 2006. Energy efficiency assessment for the Antalya Region hotels in Turkey. Energ Buildings 38, 964-971.

779 Perch-Nielsen, S., Sesartic, A., Stucki, M., 2010. The greenhouse gas intensity of the tourism sector: 
Raggi, A., Sára, B., Petti, L., 2005. Life Cycle Assessment case studies in small and medium sized enterprises offering tourist accommodation services., 12th SETAC Europe LCA Case Studies Symposium, Bologna, Italy, pp. 171-174.

784 Rebitzer, G., Fullana-i-Palmer, P., Jolliet, O., Klopffer, W., 2001. Advances in LCA and LCM: An update on the liaison of the two LCA-Planets. International Journal of Life Cycle Assessment 6, 187191.

Rosselló, B., Moia, A., Cladera, A., Martinez, V., 2008. Improving the Environmental Sustainability of hotel buildings through the analysis ofits Life Cycle. Case Study:Balearic Islands. Initial phase, International Conference on Renewable Energies and Power Quality, Santander, Spain.

790 Rosselló-Batle, B., Moià, A., Cladera, A., Martínez, V., 2010. Energy use, CO2 emissions and waste 791 throughout the life cycle of a sample of hotels in the Balearic Islands. Energ Buildings 42, 547-558.

792 Santamouris, M., Balaras, C.A., Dascalaki, E., Argiriou, A., Gaglia, A., 1996. Energy conservation and retrofitting potential in Hellenic hotels. Energ Buildings 24, 65-75.

794 Scheuer, C., Keoleian, G.A., Reppe, P., 2003. Life cycle energy cycle energy and environmental performance of a new university building: modeling challenges and design implications. Energ Buildings 35, 1049-1064.

Sun, Y., 2014. A framework to account for the tourism carbon footprint at island destinations. Tourism 798 Management 45, 16-27.

SUTOUR, 2007. Environmental initiatives by European tourism businesses Instruments, indicators and practical examples. LIFE04 ENV/D/000055 Project.

801 Thinkstep, 2015. GaBi 6 software and professional databases (Ecoinvent 3.0; PE International, 2015; 802 plastics Europe; ILCD; etc.), Leinfelden-Echterdingen, Germany.

803 Trung, D.N., Kumar, S., 2005. Resource use and waste management in Vietnam hotel industry. Journal 804 of Cleaner Production 13, 109-116.

805 UNEP, 2017. Consultation Document. Recommended key environmental indicators for the tourism private sector. (Draft Prepared for Discussion at A UNFCCC COP22 Tourism Side Event Consultation Meeting; Palmeraie Golf Palace Resort Hotel, Marrakech, Morocco; 10th November 2016), UN Environment (Economy Division), Tourism \& Environment Programme, Responsible Industry \& Value Chain Unit (RIVU), Paris, France.

810 UNEP/SETAC, 2012. Greening the Economy through Life Cycle Thinking - 10 Years of the 811 UNEP/SETAC Life Cycle Initiative. 60p, Paris, France.

812 UNWTO, 2008. Climate change and tourism: Responding to global challenges. United Nations World 813 Tourism Organization, Madrid.

814 UNWTO, 2015. Tourism Highlights. United Nations World Tourism Organization, Madrid, Spain.

815 UNWTO, 2016. Tourism Highlights. United Nations World Tourism Organization, Madrid, Spain.

816 Watson, J., Sastre, F., Raya, J.M., Ayuso, S., Fullana-i-Palmer, P., 2009. Sustainability impact 817 assessment of a tourist visiting Majorca using LCA, LCC and Social LCA, 4th International

818 Conference on Life Cycle Management: The Global Challenge of Managing Life Cycles, Cape Town, 819 South Africa.

820 WWF-UK, 2002. Holiday footprinting: A practical tool for responsible tourism. 821 http://www.wwf.org.uk/filelibrary/pdf/holidayfootprintingfull.pdf. 